of heroin administration, and examine possible interactions between baseline characteristics of patients and relative benefit of heroin treatment.

Contributors: TVP (coguarantor) had ultimate responsibility for the evaluation of the programme; he proposed and finalised the evaluation design, assisted with data collection procedures and data quality control, analysed the data, and wrote the paper. FG managed the experimental programme; he assisted with study design, conducted or supervised data collection, checked quality of data, discussed implications of results, and revised the paper. MdR wrote the detailed study protocol, negotiated acceptability of randomised study with authorities, discussed implications of results, and revised the paper. AM (coguarantor) had ultimate responsibility for the experimental programme; she helped with and approved the study protocol, negotiated acceptability of randomised study with authorities, discussed implications of results, and contributed to the paper.

Funding: Federal Office of Public Health (Berne, Switzerland), Swiss National Science Foundation (Berne, Switzerland, career development grant 3233-32609.91 to TVP).

Conflict of interest: None.

1 Stimson GV, Oppenheimer E. Heroin addiction. Treatment and control in Britain. London: Tavistock Publications, 1982

Ostini R, Bammer G, Dance PR, Goodin RE. The ethics of experimental heroin maintenance. J Med Ethics 1993;19:175-82.

3 Nadelmann EA. Drug prohibition in the United States: costs, consequences, and alternatives. Science 1989·245:939-47.

4 Farrell M, Ward J, Mattick R, Hall W, Stimson GV, des Jarlais D, et al. Methadone maintenance treatment in opiate dependence: a review. $B M J$ 1994;309:997-1001.

5 Koran LM. Heroin maintenance for heroin addicts: issues and evidence. N Engl J Med 1973;288:654-60.

6 Mino A. Scientific analysis of the literature on the controlled provision of heroin or morphine [in French]. Berne: Federal Office of Public Health, 1990.
7 Hartnoll RL, Mitcheson MC, Battersby A, Brown G, Ellis M, Fleming P, et al. Evaluation of heroin maintenance in controlled trial. Arch Gen Psychiatry 1980;37:877-84.

8 Ghodse AH. Treatment of drug addiction in London. Lancet 1983;i:636-9.

9 Strang J, Gossop M. Heroin addiction and drug policy: the British system. New York: Oxford University Press, 1994.

10 Lewis E. A heroin maintenance programme in the United States? JAMA 1973;223:539-46.

11 Bammer G, Douglas RM. The ACT heroin trial proposal: an overview. Med J Austr 1996;164:690-2.

12 Sheldon T. Dutch report advises prescribing heroin for misusers. BMJ 1995;310:1625.

13 Rihs-Middel M, ed. Swiss Federal Office of Public Health. The medical prescription of narcotics. Scientific foundations and practical experiences. Bern: Hogrefe and Huber Publishers, 1996.

14 Uchtenhagen A. Diversified prescription of narcotics to heroin addicts: background, design, research plan [in German]. Schweiz Rundsch Med Prax 1994;83:931-6.

15 Jenkinson C, Coulter A, Wright L. Short form 36 (SF-36) health survey questionnaire: normative data for adults of working age. BMJ 1993;306:1437-40.

16 Armitage P, Berry G. Statistical methods in medical research. 2nd ed. Oxford: Blackwell Scientific Publications, 1987.

17 Breslow NE, Day NE. Statistical methods in cancer research. Vol 1. The analysis of case-control studies. Lyons: International Agency for Research on Cancer, 1980.

18 Dole VP. Comments on "heroin maintenance". JAMA 1972;220:1493.

19 Dole VP, Nyswander M. A medical treatment for diacetylmorphine (heroin) addiction. JAMA 1965;193:80-4.

20 Dole VP, Robinson JW, Orraca J, Towns E, Searcy P, Caine E. Methadone treatment of randomly selected heroin addicts. $N$ Engl $J$ Med 1969;280:1372-5.

21 Gunne LM, Grönbladh L. The Swedish methadone maintenance programme: a controlled study. Drug Alcohol Depend 1981;7:249-56.

22 Newman RG, Whitehill WB. Double-blind comparison of methadone and placebo maintenance treatments of narcotic addicts in Hong Kong. Lancet 1979;ii:485-8.

(Accepted 6 March 1998)

\title{
Malignant spinal cord compression: prospective study of delays in referral and treatment
}

\author{
D J Husband
}

\section{Clatterbridge \\ Centre for \\ Oncology, \\ Bebington, Wirral \\ L63 4JY \\ D J Husband, \\ consultant in clinical \\ oncology}

BMJ 1998;317:18-21

\section{Abstract}

Objectives: To examine the delay in presentation, diagnosis, and treatment of malignant spinal cord compression and to define the effect of this delay on motor and bladder function at the time of treatment. Design: Prospective study of all new patients presenting to a regional cancer centre with this condition.

Setting: Regional cancer centre.

Subjects: 301 consecutive patients.

Main outcome measures: Interval from onset of symptoms to presentation and treatment, delay at each stage of referral, and functional deterioration. Results: The median (range) delay from onset of symptoms of spinal cord compression to treatment was $14(0-840)$ days. Of the total delay, $3(0-300)$ days were accounted for by patients, 3 (0-330) days by general practitioners, 4 (0-794) days by the district general hospital, and $0(0-114)$ days by the treatment unit. Initial presentation to the regional cancer centre with symptoms of malignant spinal cord compression led to a significant reduction in delay to treatment and improved functional status at the time of treatment. Deterioration of motor or bladder function $\geqslant 1$ grade occurred at the general practice stage in $28 \%(57)$ and
$18 \%$ (36) of patients, the general hospital stage in $36 \%$ (83) and 29\% (66), and the treatment unit stage in $6 \%$ (19) and 5\% (15), respectively.

Conclusions: Unacceptable delay in diagnosis, investigation, and referral occurs in most patients with malignant spinal cord compression and results in preventable loss of function before treatment. Improvement in the outcome of such patients requires earlier diagnosis and treatment.

\section{Introduction}

Metastatic malignant spinal cord compression is a major cause of morbidity in patients with cancer and often renders a previously functioning patient bedridden or in hospital for the rest of his or her life. ${ }^{1}$ The outcome of treatment is poor, with less than half of patients retaining or regaining the ability to walk and about two fifths requiring a permanent urinary catheter. ${ }^{2}$ The most important prognostic factor for functional outcome is neurological function before treatment, with about $70 \%$ of initially ambulant patients, $30 \%$ of paraparetic patients, and $5 \%$ of paraplegic patients retaining or regaining the ability to walk. ${ }^{2}$ In one review of 1392 patients, only $32 \%$ were ambulant at treatment. ${ }^{4}$ Similarly $45 \%$ of patients 
Table 1 Median (range; 95\% confidence interval) number of days to treatment of patients with malignant spinal cord compression

\begin{tabular}{|c|c|c|c|c|}
\hline Delay & All patients & $\begin{array}{l}\text { With history of malignancy } \\
(\mathrm{n}=196)\end{array}$ & $\begin{array}{l}\text { With no history of } \\
\text { malignancy ( } n=105)\end{array}$ & $P$ value ${ }^{*}$ \\
\hline From onset of back pain & 73.5 (3-1650; 60 to 89$)$ & $62(3-1650 ; 47$ to 84$)$ & $90(4-570 ; 54$ to 143$)$ & 0.0024 \\
\hline From onset of spinal cord compression & $14(0-840 ; 12$ to 17$)$ & $13(0-840 ; 9$ to 15$)$ & $20(1-30 ; 14$ to 28$)$ & 0.0016 \\
\hline From onset of weakness & $13.5(0-840 ; 10$ to 15$)$ & $10(0-840 ; 8$ to 14$)$ & $18(0-360 ; 13$ to 23$)$ & 0.0062 \\
\hline From loss of ambulation & $4.0(0-80 ; 3$ to 4$)$ & $3(0-80 ; 3$ to 4$)$ & $4(0-33 ; 2$ to 9$)$ & 0.13 \\
\hline
\end{tabular}

*History of malignancy $v$ no history, Mann-Whitney $\mathrm{U}$ test.

Table 2 Median (range; 95\% confidence interval) number of days of delay in presentation, referral, and treatment of patients with malignant spinal cord compression

\begin{tabular}{|c|c|c|c|c|}
\hline Cause of delay & All patients & With history of malignancy & With no history of malignancy & $P$ value* \\
\hline Patient & $3(0-300 ; 2$ to 4$)$ & $3(0-30 ; 2$ to 4$)$ & $4(0-78 ; 2$ to 7$)$ & 0.431 \\
\hline General practitioner & $3(0-330 ; 2$ to 4$) \dagger$ & $2(0-210 ; 1$ to 3$) \dagger$ & $4(0-330 ; 2$ to 7$) \dagger$ & 0.032 \\
\hline Hospice & $3(0-12 ; 0$ to 8$)$ & $3(0-12 ; 0$ to 8$)$ & 0 & NA \\
\hline District general hospital & $4(0-794 ; 3$ to 5$) \dagger$ & $3(0-794 ; 1$ to 5$) \dagger$ & $5(0-70 ; 3$ to 8$) \dagger$ & 0.046 \\
\hline Treatment unit & $0(0-114 ; 0) \dagger$ & $0(0-114 ; 0) \dagger$ & $0(0-15 ; 0) \dagger$ & 0.20 \\
\hline
\end{tabular}

NA $=$ not applicable.

${ }^{*}$ Mann-Whitney U test.

$+\mathrm{P}<0.0001$ Friedman test.

require a urinary catheter before treatment, and only $21 \%$ of these patients subsequently become catheter free compared with $79 \%$ of those who do not require a catheter before treatment. ${ }^{2}$

It is widely accepted that malignant spinal cord compression is a medical or surgical emergency, requiring urgent diagnosis and treatment because delay can result in irreversible paralysis or loss of sphincter function. ${ }^{56}$ Many authors, however, have referred to unnecessary and preventable delay in its diagnosis and treatment. ${ }^{78}$ While the common occurrence of severe neurological compromise at the time of treatment is well documented, the extent, cause, and effect of delay in referral and treatment are not and have therefore been investigated in the present study.

\section{Patients and methods}

I carried out a prospective study of 301 patients referred to the Clatterbridge Centre for Oncology (a regional cancer centre which is not part of a district general hospital) for treatment of a first episode of malignant spinal cord compression during a 3 year period. Six patients were excluded because it was impossible to verify most of the details of presentation and referral.

Patients were interviewed at the time of admission with a structured questionnaire, including details of the occurrence and time of onset of back pain, root pain, paraesthesia, weakness, and bladder dysfunction. The date the patient was first seen with back pain and with symptoms of spinal cord compression by the general practitioner, district general hospital, and the tertiary treatment unit (Clatterbridge Centre for Oncology or the Walton Centre for Neurosciences, Walton Hospital, Liverpool) was established by questioning the patient and cross checking with the hospital notes. Delays were expressed in terms of whole days, where a delay of $<24$ hour $=0$ days, $\geqslant 24<48$ hours $=1$ day, etc. Functional status when the patients were first seen by the general practitioner, district general hospital, and tertiary treatment centres and at the time of treatment was established in the same way and graded as follows:
Table 3 Numbers of patients delayed and extent of delay at each stage during referral

\begin{tabular}{lcccc} 
Delay (days) & $\begin{array}{c}\text { General } \\
\text { practitioner }\end{array}$ & Hospice & $\begin{array}{c}\text { District general } \\
\text { hospital }\end{array}$ & $\begin{array}{c}\text { Treatment } \\
\text { unit }\end{array}$ \\
\hline 0 & $62(30)$ & 3 & $50(21)$ & $202(67)$ \\
\hline 1 & $19(9)$ & 1 & $37(16)$ & $38(13)$ \\
\hline $2-7$ & $58(28)$ & 3 & $68(29)$ & $43(14)$ \\
\hline $8-14$ & $21(11)$ & 2 & $34(15)$ & $12(4)$ \\
\hline$>14$ & $46(22)$ & 0 & $45(19)$ & $6(2)$ \\
\hline Not assessed & 8 & 0 & 1 & 0 \\
\hline
\end{tabular}

motor function-I no weakness, II weakness, walks unaided, III walks with aids only, IV paraparesis, unable to walk, V paraplegia; and bladder function-I normal, II sphincter dysfunction, III incontinence requiring catheter.

Data were analysed with STATISTICA FOR Windows version 5.1 (Statsoft, Tulsa) and SPSS FOR Windows version 6.0 (SPSS, Chicago). The distributions of delays were strongly skewed, and the median is therefore used throughout at the summary statistic with $95 \%$ confidence intervals calculated by the binominal method. ${ }^{9}$ Two independent samples were compared with the Mann-Whitney $\mathrm{U}$ test, $\mathrm{k}$ related samples with the Friedman two way analysis of variance by ranks, $k$ independent samples with the Kruskal-Wallis one way analysis of variance, and proportions with $\chi^{2}$ test. $^{10}$

\section{Results}

Table 1 shows the delay from the onset of symptoms to treatment for all patients and for those with and without a history of malignancy. In the latter group the diagnosis of malignancy was established at the time of presentation with malignant spinal cord compression. The delay from onset of symptoms to treatment was significantly longer for patients without a history of malignancy.

Patients first presented with symptoms of spinal cord compression to the general practitioner in 205 $(68 \%)$ cases, to a hospice in four $(1 \%)$, to a district general hospital in $64(21 \%)$, and to the regional oncology centre in $28(9 \%)$. During the referral process 214 $(78 \%)$ patients were seem at some stage by a general 
practitioner, nine (3\%) at a hospice, $235(78 \%)$ at a district general hospital, and all 301 at the regional oncology centre. The delay from first being seen by a doctor with symptoms of spinal cord compression to treatment was shorter if the patient first presented to the oncology centre rather than to the general practitioner or district general hospital (oncology centre delay $1(95 \%$ confidence interval 0 to 1 ; range 0 -114) day; general practitioner delay 9 (7 to $13 ; 0-840$ ) days; district general hospital delay 6 (3 to 9; 0-74) days; $\mathrm{P}=0.0007$ ).

The delays during referral once the patient developed signs or symptoms of spinal cord compression are shown in table 2 . Table 3 shows that of patients seen by general practitioners, $30 \%$ were referred without delay; of those seen by the district general hospital, $21 \%$ were referred without delay, and $67 \%$ were treated without delay at the treatment units. Delays of more than 7 days occurred in 33\% of patients at the general practitioner stage, $34 \%$ at the district general hospital stage, and $6 \%$ at the treatment unit stage.

The functional status at each stage in the referral process and the number of patients who deteriorated $\geqslant 1$ grade at each stage is shown in table 4 . Initial presentation to the regional cancer centre with symptoms of spinal cord compression was associated with an increased proportion who remained ambulant at the time of treatment $(68 \%(19 / 28) v 30 \%(60 / 205)$ if they presented to a general practitioner and $28 \%(18 / 63)$ if they presented to the district general hospital, $\chi^{2} 17.2$; $\mathrm{P}<0.001)$. Similarly, $74 \%(20 / 27)$ of patients first presenting to the regional cancer centre were catheter free at treatment compared with 52\% (101/195) presenting to the general practitioner and 48\% (30/63) presenting to the district general hospital $\left(\chi^{2} 9.5\right.$; $\mathrm{P}<0.01)$.

\section{Discussion}

This study has shown that delay in the diagnosis and treatment of malignant spinal cord compression remains a common problem and results in preventable deterioration in neurological function before treatment in most patients. Only $33 \%$ of patients were still ambulant and 53\% catheter free at the time of treatment. This suggests little progress from the series reviewed by Findlay (originally reported between 1963 and 1982), in which $32 \%$ of patients were ambulant at treatment.

Though malignant spinal cord compression is widely recognised to be a medical emergency, the precise degree of urgency required remains uncertain, and this may contribute to the occurrence of unnecessary delays. In general it is reasonable to expect referral and
Key messages

- Functional outcome of malignant spinal cord compression depends on functional status at time of treatment

- Delay is associated with loss of motor and bladder function, which may be irreversible

- Unacceptable delay in diagnosis and referral is common

- The main causes of delay are failure to diagnose spinal cord compression and failure to investigate and refer urgently (within 24 hours)

- Encouraging patients to present directly to a regional cancer centre may reduce delay and improve functional status at treatment

treatment of malignant spinal cord compression in less than 24 hours, ${ }^{11}$ but this target was not achieved in this study for $70 \%$ of patients at the general practitioner stage, $79 \%$ at the district general hospital stage, and $33 \%$ at the treatment unit stage. Failure to diagnose spinal cord compression and failure to investigate, refer, and treat sufficiently urgently were the main causes of delay and the consequent functional deterioration.

The finding that initial presentation directly to the oncology centre is associated with reduced delay to treatment and improved neurological function before treatment suggests that encouragement of increased self referral by the patient to the oncology centre might be one solution to the problem, at least for those already under the care of the centre. Given that this is a complication that occurs in only $1-2 \%$ of patients with cancer it would be preferable to target patient education to those groups at high risk (for example, those with breast and prostate cancer with bone metastases, myeloma). Facilitating early referral from general practitioners and district general hospitals to radiotherapy and neurological centres is important, ${ }^{8}$ and after a preliminary analysis of the delays occurring at the Clatterbridge centre beds are now set aside to facilitate the emergency admission of patients with malignant spinal cord compression. The most important need, however, is for ongoing education to encourage clinical colleagues in all disciplines to recognise the early signs and the need for urgent referral.

This study would not have been possible without the cooperation of my consultant colleagues at the Clatterbridge Centre for Oncology and the Walton Centre for Neurosciences, Liverpool.

Table 4 Deterioration in function during referral in patients with malignant spinal cord compression

\begin{tabular}{|c|c|c|c|c|}
\hline \multirow[b]{2}{*}{ Stage } & \multicolumn{2}{|c|}{ Motor function } & \multicolumn{2}{|c|}{ Bladder function } \\
\hline & No (\%) ambulant & No $(\%)$ deteriorating $\geqslant 1$ grade & No $(\%)$ catheter free & No $(\%)$ deteriorating $\geqslant 1$ grade \\
\hline General practice & $149 / 213(70)$ & $57 / 213(28)$ & $184 / 205(90)$ & $36 / 205(18)$ \\
\hline District general hospital & $131 / 233(56)$ & $83 / 233(36)$ & $178 / 228(78)$ & $66 / 228(29)$ \\
\hline Treatment unit & $109 / 299(36)$ & $19 / 299(6)$ & $164 / 289(57)$ & $15 / 289(5)$ \\
\hline Treatment & $99 / 299(33)$ & NA & $152 / 284(52)$ & NA \\
\hline$\chi^{2}$ & & 56.3 & & 54.3 \\
\hline$P$ value & & $<0.001$ & & $<0.001$ \\
\hline
\end{tabular}

$\mathrm{NA}=$ not applicable 
Contributors: Dr I R Campbell assisted in the initial data collection. Mrs J Whiteway helped with data collection and preparation of the manuscript. $\mathrm{DJH}$ is the guarantor for the study.

Funding: Clatterbridge Cancer Research Trust.

Conflict of interest: None.

Posner JB. Neurological complications of cancer. Philadelphia: FA Davis, 1995.

2 Bach F, Larsen BH, Rohde K, Borgensen SE, Gjerris F, Boge-Rasmussen T, et al. Metastatic spinal cord compression. Acta Neurochir 1990;107:3743.

3 Gilbert RW, Kim J, Posner JB. Epidural spinal cord compression from metastatic tumour diagnosis and treatment. Ann Neurol 1978;3:40-51.

4 Findlay GFG. Adverse effects of the management of spinal cord compression. J Neurol Neurosurgery Psychiatry 1984;47:761-8.
5 Delaney TF, Oldfield EH. Spinal cord compression. In: De Vita VT, Hellman S, Rosenberg SA, eds. Cancer principles and practice of oncology. 4th ed. Philadelphia:JB Lippincott, 1993:2118-27.

6 Boogerd W, Van der Sande IJ. Diagnosis and treatment of spinal cord compression in malignant disease. Cancer Treatment Rev 1993;19:129-50

7 Byrne TN, Waxman SG. Spinal cord compression. Philadelphia: FA Davis, 1990.

8 Johnston RA. The management of acute spinal cord compression. J Neu rol Neurosurgery Psychiatry 1993;56:1046-54.

9 Campbell MJ, Gardener MJ, Altman DG, eds. Statistics with confidence. London: BMJ Publishing, 1989

10 Siegel S, Castellan NJ. Nomparametric statistics. New York: McGraw Hill, 1988.

11 Byrne TN. Spinal metastases. In: Wiley RG, ed. Neurological complications of cancer. New York: Marcel Dekker, 1995:23-44.

(Accepted 20 March 1998)

\title{
Reactions of participants to the results of a randomised controlled trial: exploratory study
}

\author{
Claire Snowdon, Jo Garcia, Diana Elbourne
}

\begin{abstract}
Objectives: To assess views of parents of babies who participated in a neonatal trial, about feedback of trial results.

Design: Qualitative analysis of interviews.

Setting: Parents' homes.

Subjects: Parents of 24 surviving babies enrolled in a

UK randomised controlled trial comparing ventilatory support by extracorporeal membrane oxygenation with conventional management.

Main outcome measures: Views about contents of results, reactions to results, effect of hindsight, and importance of feedback.

Results: Information about mortality was well understood by the parents but morbidity was less clearly reported. Even when the content was emotionally exacting, the information was still wanted as it removed uncertainty; provided an endpoint to difficult events; promoted further discussion within couples; and acknowledged their contribution to answering an important clinical question.

Conclusions: Feedback of trial results to participants should be a consideration of researchers, but a careful approach is required. This study was based on a highly selective group of parents within a particularly sensitive trial. More research is needed to assess the extent to which these results can be generalised to other trials or to groups such as bereaved parents.
\end{abstract}

\section{Introduction}

In recent years there has been a demand for the feedback of results of medical research to participants..$^{1-5}$ There are, however, practical and ethical factors to consider as results can be complicated, alarming, and distressing. Two studies examined participants' responses to results in sensitive situations where the results could induce feelings of guilt or fear. ${ }^{67}$

Epidemiological research into risk factors for paediatric brain tumours indicated an association with parental behaviour or lifestyle, or both. ${ }^{6}$ Despite concerns about the impact on parents a questionnaire based study showed that mothers said that they understood the results and viewed feedback as important. The authors concluded that feedback was not emotionally exacting, but a poor response rate undermined the validity of their findings.

When treatment is randomised feedback may be particularly problematic. While randomisation is appropriate at the start of a trial at closure uncertainty should (ideally) be resolved. Trial participants who did not receive what was shown to be the best treatment may with hindsight feel deprived or placed at risk. In a trial of surgery to lower cholesterol after myocardial infarction, where mortality was higher in the control group, a quality of life assessment showed no detrimental effects of feedback. ${ }^{7}$

Although these studies suggest that feedback of sensitive results is not problematic closer examination is needed. Our study describes the reactions of a sample of parents of surviving babies to the communication of results of a neonatal trial.

\section{United Kingdom collaborative trial of} extracorporeal membrane oxygenation

The trial compared two methods of ventilatory support for critically ill neonates with acute respiratory failure. At randomisation the babies were already receiving ventilatory support by conventional management in a neonatal intensive care unit. Conventional management was compared with oxygenation of the blood by an external circuit (extracorporeal membrane oxygenation) in one of five specialist centres. Neonatal extracorporeal membrane oxygenation was only available in the trial as it was an unevaluated treatment.

The trial showed that extracorporeal membrane oxygenation reduces the risk of early death; 30 of 93 babies allocated to extracorporeal membrane oxygenation died compared with 54 of 92 babies allocated to conventional management. ${ }^{8}$ Only one baby in each treatment group was found to have a severe disability at 1 year old.

\section{Medical Statistics Unit, London School of Hygiene and Tropical Medicine, \\ University of London, London WC1E 7HT \\ Claire Snowdon, research fellow Diana Elbourne, senior lecturer \\ National Perinatal Epidemiology Unit, University of Oxford, Radcliffe Infirmary, Oxford OX2 6HE \\ Jo Garcia, social scientist \\ Correspondence to: Ms C Snowdon, Centre for Family Research, University of Cambridge, Cambridge CB2 3RF CMS1000@ cam.ac.uk}

BMJ 1998;317:21-6 